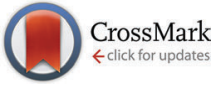

Cite this: Chem. Commun., 2016 52,6471

Received 7th March 2016, Accepted 14th April 2016

DOI: $10.1039 / \mathrm{c} 6 \mathrm{cc} 02002$

www.rsc.org/chemcomm

\section{New artificial fluoro-cofactor of hydride transfer with novel fluorescence assay for redox biocatalysis $\dagger$}

\author{
Lei Zhang, ${ }^{a}$ Jun Yuan, ${ }^{a}$ Yufang $X u^{*}{ }^{a}$ Y.-H. Percival Zhang ${ }^{{ }^{b}}$ and Xuhong Qian ${ }^{{ }^{a}}$
}

\begin{abstract}
A new artificial fluoro-cofactor was developed for the replacement of natural cofactors $N A D(P)$, exhibiting a high hydride transfer ability. More importantly, we established a new and fast screening method for the evaluation of the properties of artificial cofactors based on the fluorescence assay and visible color change.
\end{abstract}

Nicotinamide adenine dinucleotide (NAD), nicotinamide adenine dinucleotide phosphate (NADP), and their reduced forms, NADH and NADPH, are ubiquitous in all living systems because more than 400 oxidoreductases require $\mathrm{NAD}(\mathrm{P})$ as cofactors. Although there are several methods for in situ regeneration of $\mathrm{NAD}(\mathrm{P})$, including enzymatic, ${ }^{1}$ chemical, ${ }^{2}$ and electrochemical ${ }^{3}$ regeneration, the high cost and low-stability of $\mathrm{NAD}(\mathrm{P})$ urge people to find out artificial cofactors which can replace and even surpass $\mathrm{NAD}(\mathrm{P}) .{ }^{4} \mathrm{NAD}(\mathrm{P})$ contain two parts, the nicotinamide moiety acting as a hydride donor or acceptor and the adenine dinucleotide moiety playing an important role in separating between the anabolic and catabolic pathways. ${ }^{5}$ Although the anabolic and catabolic pathways are necessary for survival, it is not essential to realize hydride transfer in redox biocatalysis. Hence a number of nicotinamide-containing artificial cofactors have been reported (Fig. 1). In chemical catalysis, Hantzsch ester (HEH) successfully acts as a reductant in the asymmetric hydrogenation of benzoxazinones ${ }^{6}$ and another artificial cofactor 9,10-dihydrophenanthridine (DHPD) has been designed for the asymmetric hydrogenation of benzoxazinones, benzoxazines, quinoxalines and quinolones, resulting in excellent activities and enantioselectivities. ${ }^{7}$ Moreover, a widely-used artificial cofactor BNAH has been reported to react with oxidoreductases such as enoate reductases for $\mathrm{C}=\mathrm{C}$ bioreduction, ${ }^{8}$ and horse liver alcohol dehydrogenase for chiral synthesis. ${ }^{9}$ Most notably, Nigel et al. reported the cocrystal

\footnotetext{
${ }^{a}$ Shanghai Key Laboratory of Chemical Biology, State Key Laboratory of Bioreactor Engineering, School of Pharmacy, East China University of Science and Technology, Shanghai 200237, China. E-mail: yfxu@ecust.edu.cn; Fax: +86 21 64252603; Tel: +86 2164251399

${ }^{b}$ Biological Systems Engineering Department, Virginia Tech, 304 Seitz Hall, Blacksburg, Virginia 24061, USA

$\dagger$ Electronic supplementary information (ESI) available. See DOI: 10.1039/c6cc02002j
}
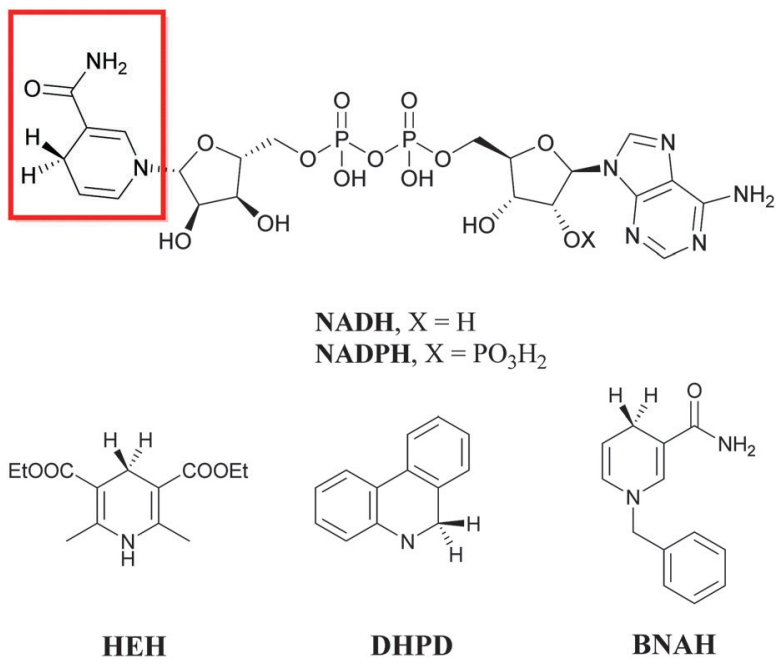

Fig. 1 Structures of $\mathrm{NAD}(\mathrm{P}) \mathrm{H}$ and reported artificial cofactors.

structures of flavin-containing enzyme ene reductases (ERs) from the Old Yellow Enzyme family (EC 1.3.1.31) in complex with $\mathrm{NADH}$ and the representative artificial cofactor, validating that both natural and artificial cofactors shared a similar $\pi-\pi$ stacking effect and occupied the same region of the active sites. ${ }^{10}$

Inspired by these discoveries, here we reported novel artificial cofactors based on the 1,4-dihydropyridine skeleton. These artificial redox coenzymes are inexpensive to synthesize and stable enough to prolong the lifetime of enzymatic fuel cells ${ }^{11}$ with lower potential than NADH. Due to the wide application of fluorine in drug discovery and development, we also introduced fluorine in our scaffold to expand the properties and synthetic methodologies which surprisingly produce a more facile access to a wide range of fluorinated artificial cofactors. These artificial cofactors allow the replacement of $\mathrm{NAD}(\mathrm{P}) \mathrm{H}$ to transfer the hydride to the reductase despite their apparently minimal structures to the native coenzymes. These artificial cofactors may be applied in sugar-powered biobatteries, while boosting the development of artificial catalysts in asymmetric synthesis. 


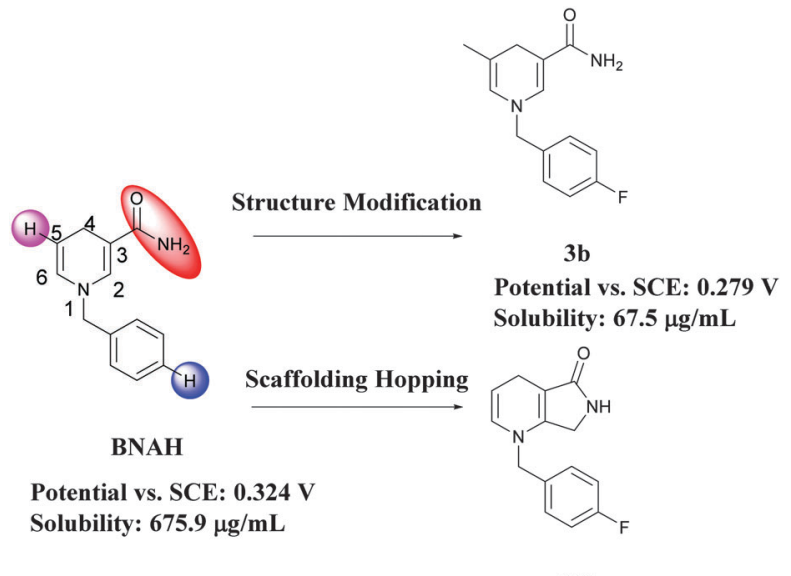

$15 \mathrm{~b}$

Potential vs. SCE: $0.543 \mathrm{~V}$

Solubility: $424.9 \mu \mathrm{g} / \mathrm{mL}$

Fig. 2 Diagram for the structural optimization strategy.

Moreover, in view of the complicated existing evaluation methodology of artificial cofactors, we chose a substrate that could give a remarkable color change after specific reduction.

Each artificial cofactor has a unique potential, $E$, that indicates the ability of the compound to donate or accept electrons. ${ }^{5}$ In order to lower its reducing potential, much focus has been emphasized on the structure modification and scaffold hopping of the 1,4-dihydropyridine skeleton (Fig. 2).

First, we focused on the modification of the C-3 position with different substituents on the pyridine ring, whose position is the most important, owing to its role as the coordinating center in the active catalytic pocket of the reductase. ${ }^{9}$ We replaced $-\mathrm{CONH}_{2}$ with $-\mathrm{CSNH}_{2}$ and $-\mathrm{COOCH}_{3}$ in $\mathrm{C}-3$ position of the 1,4-dihydropyridine skeleton because they have more tightness coordination ability with reductase. ${ }^{12}$ In order to screen skeletons and further optimize the hydride transfer capability of new artificial cofactors, we designed a five member lactam ring with an immobilized intramolecular amide bond which could strengthen $\pi-\pi$ stacking with the reductase. Second, we attempted to introduce methyl on the C-5 position because methyl could inhibit protonation of the 5,6-double bond with less negative effect on the hydride transfer ability to $\mathbf{C 4}(\mathbf{8 b} v s$. 11b) (Table 1). ${ }^{13}$ Third, according to known literature, ${ }^{14}$ the 1-benzyl substituent on the nitrogen atom at the ring exerted a substantial electron-withdrawing effect that could favorably strengthen the hydride transfer ability to C4. Hence, we introduced a highly electronegative group ether side chain and a fluorine atom to facilitate transferring the hydride. As a kind of conformational element in vivo, the introduction of $\mathrm{F}$ will lead to an effect on the benzyl conformation and influence the binding mode with the receptor. ${ }^{15}$ Notably, the small size of fluorine may probably not disturb the artificial cofactor entry into pockets.

The preparation of 1,4-dihydropyridine analogues started with commercially available substituted nicotinamide, methyl nicotinate, thionicotinamide and $\mathbf{1 2} .{ }^{16}$ Through two straightforward steps, substituted nicotinamides were alkylated using benzyl bromide ${ }^{17}$ in THF or $\mathrm{CH}_{3} \mathrm{CN}$ to obtain bromide salts and reduced using $\mathrm{Na}_{2} \mathrm{~S}_{2} \mathrm{O}_{4}$ to yield 1,4-dihydropyridines (2b-16b) (Scheme 1). ${ }^{18}$
Table 1 Potential and solubility of biomimetic cofactors

\begin{tabular}{|c|c|c|c|c|c|}
\hline Compound & $\mathrm{R}_{1}$ & $\mathrm{R}_{2}$ & $\mathrm{R}_{3}$ & $\begin{array}{l}E^{a} \text { potential } \\
(\mathrm{V}) \text { vs. SCE }\end{array}$ & $\begin{array}{l}\text { Solubility }^{b} \\
\left(\mu \mathrm{g} \mathrm{mL}^{-1}\right)\end{array}$ \\
\hline & & NADH & & 0.551 & $>10^{4}$ \\
\hline 1 (BNAH) & $\mathrm{H}$ & $\mathrm{CONH}_{2}$ & $\mathrm{H}$ & 0.324 & 675.9 \\
\hline $2 \mathrm{~b}$ & $\mathrm{CH}_{3}$ & $\mathrm{CONH}_{2}$ & $\mathrm{H}$ & 0.312 & 298.4 \\
\hline $3 \mathbf{b}$ & $\mathrm{CH}_{3}$ & $\mathrm{CONH}_{2}$ & $\mathrm{~F}$ & 0.279 & 67.5 \\
\hline $4 b$ & $\mathrm{CH}_{3}$ & $\mathrm{CONH}_{2}$ & $\mathrm{OCH}_{2} \mathrm{CH}_{2} \mathrm{OCH}_{3}$ & 0.348 & 705.5 \\
\hline $5 b$ & $\mathrm{H}$ & $\mathrm{CSNH}_{2}$ & $\mathrm{H}$ & 0.451 & 89.1 \\
\hline $6 b$ & $\mathrm{H}$ & $\mathrm{CSNH}_{2}$ & $\mathrm{~F}$ & 0.425 & $<10$ \\
\hline $7 \mathbf{b}$ & $\mathrm{H}$ & $\mathrm{CSNH}_{2}$ & $\mathrm{OCH}_{2} \mathrm{CH}_{2} \mathrm{OCH}_{3}$ & 0.508 & 100.5 \\
\hline $8 \mathbf{b}$ & $\mathrm{H}$ & $\mathrm{COOCH}_{3}$ & $\mathrm{H}$ & 0.420 & 115.8 \\
\hline $9 b$ & $\mathrm{H}$ & $\mathrm{COOCH}_{3}$ & $\mathrm{~F}$ & 0.363 & 32.9 \\
\hline $10 b$ & $\mathrm{H}$ & $\mathrm{COOCH}_{3}$ & $\mathrm{OCH}_{2} \mathrm{CH}_{2} \mathrm{OCH}_{3}$ & 0.408 & 62.8 \\
\hline 11b & $\mathrm{CH}_{3}$ & $\mathrm{COOCH}_{3}$ & $\mathrm{H}$ & 0.349 & 30.9 \\
\hline $12 b$ & $\mathrm{CH}_{3}$ & $\mathrm{COOCH}_{3}$ & $\mathrm{~F}$ & 0.318 & $<10$ \\
\hline 13b & $\mathrm{CH}_{3}$ & $\mathrm{COOCH}_{3}$ & $\mathrm{OCH}_{2} \mathrm{CH}_{2} \mathrm{OCH}_{3}$ & 0.336 & 100.2 \\
\hline $14 b$ & & & $\mathrm{H}$ & 0.578 & 918.7 \\
\hline 15b & & & $\mathrm{F}$ & 0.543 & 424.9 \\
\hline $16 b$ & & & $\mathrm{OCH}_{2} \mathrm{CH}_{2} \mathrm{OCH}_{3}$ & 0.563 & 964.9 \\
\hline
\end{tabular}

${ }^{a}$ Potential of artificial cofactors and NADH recorded at a glassy carbon electrode. The voltage scan rate was $100 \mathrm{mV} \mathrm{s}^{-1} \cdot{ }^{b}$ Solubility of biomimetic cofactors conducted using UV-visible spectrophotometer in $0.1 \mathrm{M}$ PBS buffer, pH 7.4.

Substitution with $\mathrm{F}$ at the para-position of 1-benzyl yielded 12b, which displays a lower potential than 11b due to an electronwithdrawing effect as we expected ( $3 \mathbf{3}$ vs. $\mathbf{2 b}, \mathbf{6 b} v s . \mathbf{5 b}, \mathbf{9 b} v s . \mathbf{8 b}$, 15b vs. 14b) (Table 1 and Fig. S1, ESI $\dagger$ ). Besides, sugar-powered biobatteries usually run on the aqueous buffer so we determined the water solubility of artificial cofactors. Though the introduction of F may sacrifice the solubility to some extent, the solubility of 15b is just a bit lower than that of BNAH, without impeding the use of this artificial cofactors.

To appraise the hydride transfer capability of our artificial cofactors, we utilized the hydrogenation of $\alpha, \beta$-epoxy ketones to $\beta$-hydroxy ketones mediated through a catalytic amount of artificial cofactors in a chemical system to evaluate the hydride

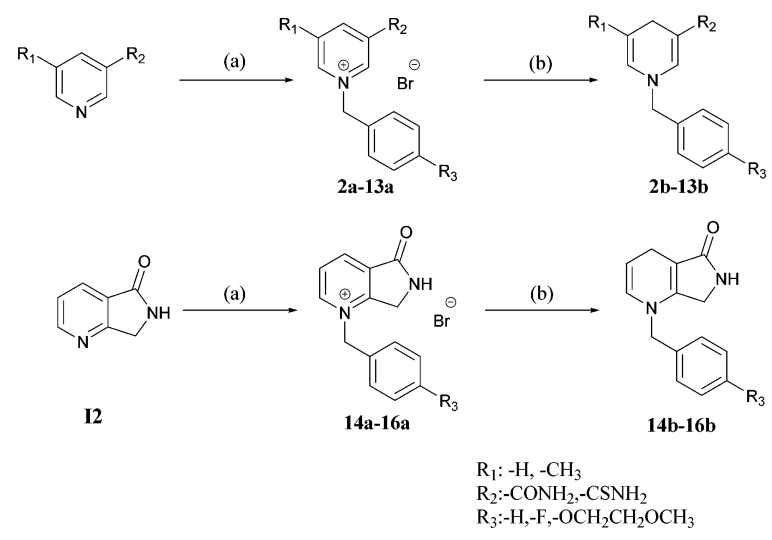

Scheme 1 Reactions and conditions: (a) benzyl bromide, $\mathrm{CH}_{3} \mathrm{CN}$ or THF reflux for $6 \mathrm{~h}$; (b) $\mathrm{NaHCO}_{3}, \mathrm{Na}_{2} \mathrm{~S}_{2} \mathrm{O}_{4}, \mathrm{H}_{2} \mathrm{O}$, in dark, Ar at rt for $3 \mathrm{~h}$. 
Table 2 Evaluation of the artificial cofactors through a chemistry method

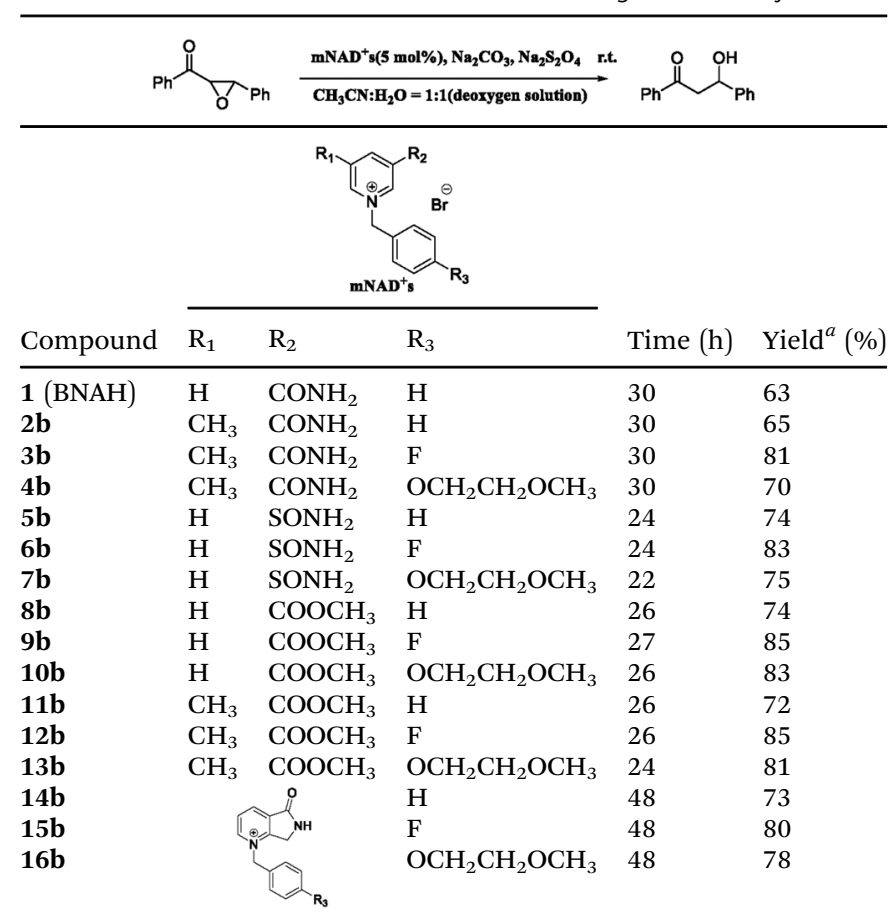

${ }^{a}$ Isolated yield through flash column chromatography. Reactions were conducted in deoxygenated $\mathrm{CH}_{3} \mathrm{CN}: \mathrm{H}_{2} \mathrm{O}(1: 1, \mathrm{v} / \mathrm{v})$ at room temperature.

transfer ability of our artificial cofactors. ${ }^{19}$ In this enzyme-free reaction, $\mathrm{Na}_{2} \mathrm{~S}_{2} \mathrm{O}_{4}$ was used as the reducing agent to regenerate BNAH from $\mathrm{BNA}^{+} \mathrm{Br}^{-}$, with $\mathrm{H}_{2} \mathrm{O}$ as the hydride source, and the best optimized condition is $\mathrm{CH}_{3} \mathrm{CN} / \mathrm{H}_{2} \mathrm{O}(1: 1, \mathrm{v} / \mathrm{v})$ at $25{ }^{\circ} \mathrm{C}$, giving complete conversion with high isolated yields.

As shown in Table 2, all artificial cofactors could transfer hydrides to form $\beta$-hydroxy ketones, and the isolated yields of the best promising compounds such as $\mathbf{9 b}$ and $\mathbf{1 2} \mathbf{b}$ are up to $85 \%$ higher than positive control BNAH (63\%), which outperforms natural coenzymes through steady-state-kinetics. ${ }^{10}$ The reaction rates of compounds $\mathbf{5} \mathbf{b}-\mathbf{7 b}$ are faster than those of other compounds, strongly suggesting that a better $\sigma$-donor $S$ in this position could the shorten reaction time indeed. We were pleased to find that all artificial cofactors could realize hydrogenation of $\alpha, \beta$-epoxy ketones to form $\beta$-hydroxy ketones under these optimized reaction conditions, which means that our artificial cofactors could act as hydride donors in this chemistry system. Besides, among these five series of cofactors, fluoro-cofactors displayed higher isolated yields than the cofactors substituted with $\mathrm{H}$ and $-\mathrm{OCH}_{2} \mathrm{CH}_{2} \mathrm{OCH}_{3}$. These phenomena were consistent with the results of cyclic voltammetry, indicating the advantage of the introduction of fluorine.

Furthermore, we designed a new assay to evaluate artificial cofactors that could react with the reductase. This new assay was better than current assays, such as UV-visible absorption spectra, GC analyses, HPLC, steady-state kinetics. We selected a flavincontaining enzyme nitroreductase (NTR) from Escherichia coli and a fluorescence quenched substrate that will give fluorescence signals observed by the naked eye if reduced. Through the optical signal, we can judge whether the artificial cofactor can react with nitroreductase for hydride transfer (Fig. 3).

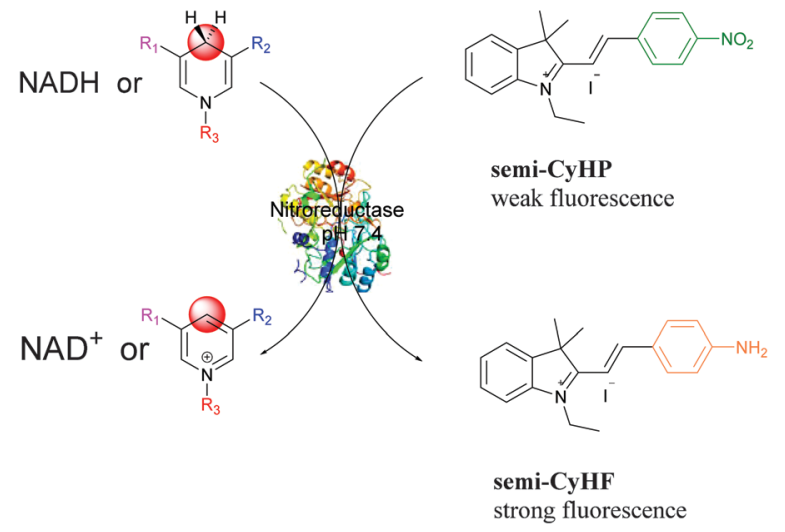

Fig. 3 Reaction mechanism of synthetic artificial cofactors.

NTR could effectively reduce nitroaromatic compounds to the corresponding amines in the presence of NADH as an electron donor by transferring the hydride. NTR exhibits an equal capability of using either NADH or NADPH as a cofactor. Richard et al. demonstrated that the adenine, dinucleotide moiety, were not necessary and NTR could recognize simple 1,4-dihydropyridine compounds as effective as $\mathrm{NAD}(\mathrm{P}) \mathrm{H}$ in its ability to transfer hydride. ${ }^{20}$

Our group previously reported that semi-CyHP could be used as a selective off-on fluorescent probe which could detect NTR. Until reduction using NADH and catalyzed by NTR, the amino group of semi-CyHF reconstructed the electronic push-pull system and a strong fluorescence was observed. ${ }^{21}$ Without NADH or replacing NADH with other biological reductants such as glutathione (GSH), homocysteine (Hcy), dithiothreitol (DTT), or cysteine (Cys), no remarkable enhancement could be obtained. This result demonstrated the importance of NADH in this system for transferring the hydride to NTR. These results suggested that a fluorescence spectroscopy response could be used to evaluate the effects of our artificial cofactors.

The assay of artificial cofactors toward the reduction of semi-CyHP was performed in phosphate buffered saline (PBS) buffer at $37{ }^{\circ} \mathrm{C}$. The fluorescence of the semi-CyHP solution $\left(10^{-5} \mathrm{M}\right)$ was undetectable when excited at around $490 \mathrm{~nm}$. After addition of $2.5 \mu \mathrm{g} \mathrm{mL} \mathrm{mL}^{-1}$ of NTR and $5 \times 10^{-4} \mathrm{M} \mathrm{NADH}$, strong fluorescence enhancement at around $575 \mathrm{~nm}$ was observed. The reduction of the semi-CyHP probe was realized and the reductive product semi-CyHF was formed as expected. By utilizing this three-component biocatalytic system which selectively responds to NADH, we could replace NADH with our artificial cofactors (2b-16b) (Fig. S2, ESI $\dagger$ ) to appraise the effects of artificial cofactors based on fluorescence enhancement. The widely-used artificial cofactor BNAH could increase the fluorescence intensity by a 5 -fold. But a 12 -fold enhancement in the fluorescence emission at $575 \mathrm{~nm}$ was observed by incubating semi-CyHP with 14b, 15b, 16b and NTR (Fig. 4). This result could be ascribed to the enhanced $\pi-\pi$ stacking effect of the pyrido dihydropyrrolo scaffold $(\mathbf{1 4 b}, \mathbf{1 5 b}, \mathbf{1 6 b})$ rather than to BNAH. These results strongly suggest that an appropriate, convenient, visible and high resolution evaluation system has 


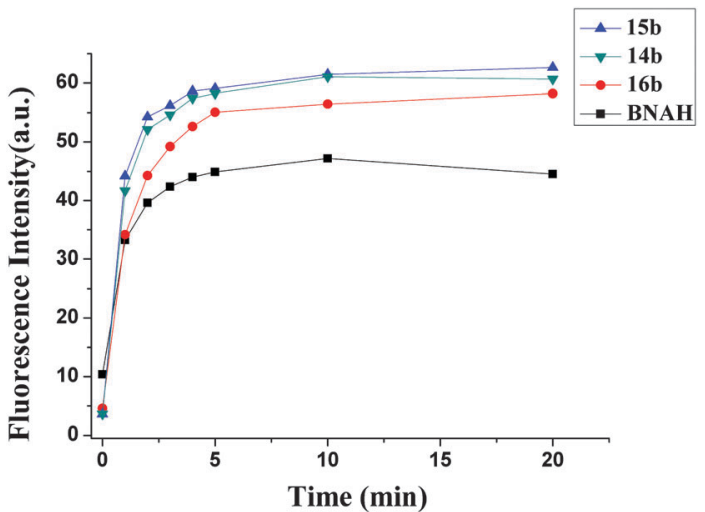

Fig. 4 Fluorescence response of probe semi-CyHP $\left(10^{-5} \mathrm{M}\right)$ after adding the artificial cofactors $\left(5 \times 10^{-4} \mathrm{M}\right)$ and NTR $\left(2.5 \mu \mathrm{g} \mathrm{mL}^{-1}\right)$ in $0.1 \mathrm{M}$ PBS buffer $(\mathrm{pH} 7.4)$ with $1 \%(\mathrm{v} / \mathrm{v}) \mathrm{DMSO}$ at $37^{\circ} \mathrm{C}$. The fluorescence intensity data were collected after certain time intervals at around $575 \mathrm{~nm}$ as indicated in the figure with excitation at $490 \mathrm{~nm}$. Silt: 10, $10 \mathrm{~nm}$.

been established to appraise the hydride transfer ability of the artificial cofactors. These pyrido dihydropyrrolo analogues could combine more tightly with NTR so that the could realize the reduction of the nitro group in semi-CyHP, inducing a change of color noticed by the naked eye and a 12-fold enhancement of the fluorescence intensity.

In summary, through rational design, we developed a novel class of artificial cofactors with low potential and good solubility. Moreover, we have established a valid evaluation method based on a fluorescence sensor to evaluate the hydride transfer ability when co-working with a flavin-containing enzyme. This novel assessment system, to the best of our knowledge, was found for the first time. These results prove that $\mathbf{1 4 b}, \mathbf{1 5 b}, \mathbf{1 6 b}$ have a better hydride transfer ability than the widely-used artificial cofactor BNAH. The introduction of fluorine into pyrido dihydropyrrolo analogues results in 15b, featuring several advantages, a lower reduction potential than that of $\mathrm{NADH}$, a high isolated yield in a chemical system and a 12-fold enhancement of the fluorescence intensity in biocatalysis.

This work is financially supported by the National Natural Science Foundation of China (Grants 21236002).

\section{Notes and references}

1 K. Hofstetter, J. Lutz, I. Lang, B. Witholt and A. Schmid, Angew. Chem., Int. Ed., 2004, 43, 2163; X. Tong, B. El-Zahab, X. Zhao, Y. Liu and P. Wang, Biotechnol. Bioeng., 2011, 108, 465; S. L. Pival, M. Klimacek and B. Nidetzky, Adv. Synth. Catal., 2008, 350, 2305.

2 H. Maid, P. Böhm, S. M. Huber, W. Bauer, W. Hummel, N. Jux and H. Gröger, Angew. Chem., Int. Ed., 2011, 50, 2397; F. Hollmann, B. Witholt and A. Schmid, J. Mol. Catal. B: Enzym., 2002, 19, 167; Y. Maenaka, T. Suenobu and S. Fukuzumi, J. Am. Chem. Soc., 2011, 134, 367; J. J. Soldevila-Barreda, P. C. Bruijnincx, A. Habtemariam, G. J. Clarkson, R. J. Deeth and P. J. Sadler, Organometallics, 2012, 31, 5958; S. Betanzos-Lara, Z. Liu, A. Habtemariam, A. M. Pizarro, B. Qamar and P. J. Sadler, Angew. Chem., Int. Ed., 2012, 124, 3963.

3 W. Ma, D.-W. Li, T. C. Sutherland, Y. Li, Y.-T. Long and H.-Y. Chen, J. Am. Chem. Soc., 2011, 133, 12366; M. Hambourger, M. Gervaldo, D. Svedruzic, P. W. King, D. Gust, M. Ghirardi, A. L. Moore and T. A. Moore, J. Am. Chem. Soc., 2008, 130, 2015.

4 J. A. Rollin, T. K. Tam and Y. H. P. Zhang, Green Chem., 2013, 15, 1708.

5 C. E. Paul, I. W. Arends and F. Hollmann, ACS Catal., 2014, 4, 788.

6 Q.-A. Chen, M.-W. Chen, C.-B. Yu, L. Shi, D.-S. Wang, Y. Yang and Y.-G. Zhou, J. Am. Chem. Soc., 2011, 133, 16432.

7 Q.-A. Chen, K. Gao, Y. Duan, Z.-S. Ye, L. Shi, Y. Yang and Y.-G. Zhou, J. Am. Chem. Soc., 2012, 134, 2442.

8 C. E. Paul, S. Gargiulo, D. J. Opperman, I. Lavandera, V. GotorFernández, V. Gotor, A. Taglieber, I. W. Arends and F. Hollmann, Org. Lett., 2012, 15, 180.

9 H. C. Lo and R. H. Fish, Angew. Chem., Int. Ed., 2002, 41, 478.

10 T. Knaus, C. E. Paul, C. W. Levy, S. de Vries, F. G. Mutti, F. Hollmann and N. S. Scrutton, J. Am. Chem. Soc., 2016, 138, 1033.

11 Z. Zhu, T.-K. Tam, F. Sun, C. You and Y. H. P. Zhang, Nat. Commun., 2014, 5, 3026.

12 H. C. Lo, O. Buriez, J. B. Kerr and R. H. Fish, Angew. Chem., Int. Ed., 1999, 38, 1429.

13 P. L. Hentall, N. Flowers and T. D. H. Bugg, Chem. Commun., 2001, 2098.

14 H. C. Lo, C. Leiva, O. Buriez, J. B. Kerr, M. M. Olmstead and R. H. Fish, Inorg. Chem., 2001, 40, 6705.

15 L. E. Zimmer, C. Sparr and R. Gilmour, Angew. Chem., Int. Ed., 2011, 50, 11860; H.-J. Boehm, D. Banner, S. Bendels, M. Kansy, B. Kuhn, K. Mueller, U. Obst-Sander and M. Stahl, ChemBioChem, 2004, 5, 637; P. Shah and A. D. Westwell, J. Enzyme Inhib. Med. Chem., 2007, 22, 527; E. P. Gillis, K. J. Eastman, M. D. Hill, D. J. Donnelly and N. A. Meanwell, J. Med. Chem., 2015, 58, 8315.

16 U. Galli, O. Mesenzani, C. Coppo, G. Sorba, P. L. Canonico, G. C. Tron and A. A. Genazzani, Eur. J. Med. Chem., 2012, 55, 58.

17 P. Moutevelis-Minakakis, E. Papavassilopoulou and T. Mavromoustakos, Molecules, 2012, 18, 50.

18 D. Mauzerall and F. Westheimer, J. Am. Chem. Soc., 1955, 77, 2261. 19 H.-J. Xu, Y.-C. Liu, Y. Fu and Y.-D. Wu, Org. Lett., 2006, 8, 3449.

20 R. J. Knox, F. Friedlos, M. Jarman, L. C. Davies, P. Goddard, G. M. Anlezark, R. G. Melton and R. F. Sherwood, Biochem. Pharmacol., 1995, 49, 1641.

21 J. Yuan, Y.-Q. Xu, N.-N. Zhou, R. Wang, X.-H. Qian and Y.-F. Xu, RSC Adv., 2014, 4, 5620. 